\title{
Maioridade penal no Brasil
e na Espanha: o pêndulo
punitivo sobre
os adolescentes infratores \\ Criminal majority in Brazil and Spain: the punitive pendulum under the juvenile offenders \\ Roberto Bassan Peixoto*
}

\begin{abstract}
Resumo - A abordagem recai em discussão acerca da redução da maioridade penal na Espanha e no Brasil, com base nos dados e estudos realizados durante o estágio doutoral na Universidade Autônoma de Barcelona, sendo fruto da pesquisa junto ao Doutorado em Serviço Social da Universidade do Estado do Rio de Janeiro (Uerj). Assim, busca-se a compreensão das alternativas para a privação de liberdade: princípio educativo x punição, reforçando os conceitos e a necessidade da luta em defesa da não punição e encarceramento em massa da juventude. Nesse contexto, são apresentadas discussões e argumentos contrários à redução da maioridade penal, com demonstração de dados e estudos nos dois países, em que se evidencia que a maioridade penal no Brasil e na Espanha abarca um pêndulo punitivo sobre os adolescentes infratores.

Palavras-chave: redução da maioridade penal; medidas socioeducativas; adolescentes infratores; socioeducação; políticas públicas; Brasil; Espanha.
\end{abstract}

\begin{abstract}
The approach falls on the discussion about the reduction of the penal age in Spain and Brazil, based on the data obtained during the doctoral training at the Autonomous University of Barcelona as a result of the research with the PhD in Social Work of the State University of Rio de Janeiro - UERJ, and seeks to understand the alternatives to deprivation of liberty: an educational principle $x$ punishment. It reinforces the concepts and the necessity of the fight in defense of the non-punishment and mass incarceration of the youth. In this context it is presented the discussions and arguments against the reduction of the criminal majority, with presentation of data and studies in both countries, where it shows that the criminal majority in Brazil and Spain covers a punitive pendulum under the juvenile offenders.

Keywords: Reduction of the Penal Majority; Educational measures; Adolescents Offenders; Socioeducation; Public policy; Brazil; Spain.
\end{abstract}

\footnotetext{
* Doutor em Serviço Social pela Universidade do Estado do Rio de Janeiro (UERJ/RJ). Doutorado Sanduíche junto ao Departamento de Sociologia da Universidade Autônoma de Barcelona - UaB, na Espanha. Atualmente é Coordenador de Gestão e Comunicação da Superintendência Estadual de Atendimento Socioeducativo (SEAS) do Governo do Estado do Ceará. E-mail: <robertobpeixoto@uol.com.br>. ORCID: <https://orcid.org/0000-0002-5554-7842>.
} 
Para efetuarmos uma análise referente ao contexto das mudanças e discussões sobre a redução da idade penal e os modelos de política pública espanhola de atendimento ao adolescente infrator frente ao modelo de atendimento socioeducativo a adolescentes infratores no Brasil, houve um cuidado para que não fosse estabelecido um estudo comparativo. É preciso levar em consideração que estamos diante de contextos históricos, modelos políticos e práticas estatais completamente diferentes. Nesse sentido, desafiamo-nos a renunciar a definições anteriores e generalizadas, e partir para uma análise que referencie as experiências nos diferentes contextos, a partir das suas realidades.

Tal pesquisa é encontrada na íntegra na tese de doutorado em Serviço Social intitulada Socioeducação e violação de direitos: o simulacro do Sistema Nacional de Atendimento Socioeducativo (Sinase) no Brasil do século XXI, publicada pela Universidade do Estado do Rio de Janeiro (Uerj). Esse estudo contou com a realização de estágio doutoral sanduíche, feito pelo autor, junto à Universidade Autônoma de Barcelona, e possui um capítulo sobre o atendimento a adolescentes na Espanha e convergências. Desse modo, aponta contradições, limites e mediações entre a política de atendimento a menores infratores na Espanha e o Sistema Nacional de Atendimento Socioeducativo no Brasil, aqui com o recorte sobre a temática central da maioridade penal, ou da redução da idade penal, a partir da abordagem da justiça juvenil nos dois países.

\section{As alternativas para a privação de liberdade: princípio educativo $x$ punição}

Para além das terminologias, o elemento-chave que merece destaque é a maior quantidade de alternativas de intervenções técnicas previstas na legislação para responsabilização do menor infrator, que vão para além do universo punitivo, como no Brasil. Logo, na prática, a grande maioria dos adolescentes não é privada de liberdade pelo cometimento de atos infracionais; antes, porém, são privilegiadas outras alternativas, utilizando a internação do adolescente em regime fechado somente em casos extremos.

No Brasil, as medidas socioeducativas previstas no Estatuto da Criança e do Adolescente (ECA), em seu artigo 112, são: advertência; obrigação de reparar o dano; prestação de serviços à comunidade; liberdade assistida; inserção em regime de semiliberdade e internação em estabelecimento educacional (BRASIL, 1990). Dentre o arcabouço de possibilidades previstas na LORPM n. 5/2000 (ESPANHA, 2000a), destacamos 13, a saber:

1) internamiento en régimen cerrado; 2) internamiento en régimen semiabierto; 3 ) internamiento en régimen abierto; 4) internamiento 
terapéutico; 5) tratamiento ambulatorio; 6) asistencia a un centro de día; 7) permanencia de fin de sema na; 8) libertad vigilada; 9) convivencia con otra persona, familia o grupo educativo; 10) prestaciones en benefício de la comunidad; 11 ) realización de tareas socioeducativas; 12) amonestación; 13) privación del permiso de conducir ciclomotores o vehículos a motor.

Além do número superior de alternativas à privação de liberdade, conceitualmente, a própria legislação LORPM n. 5/2000 (ESPANHA, 2000a) estabelece que as medidas de privação de liberdade são: a internação em regime fechado, a internação em regime semiaberto, a internação em regime aberto e a permanência de fim de semana, deixando claro o caráter sancionatório e de responsabilização dessas medidas. Ou seja, não se fala em restrição de liberdade, ampliando o conceito de regime de privação de liberdade para toda e qualquer ação que exerça coerção no direito de ir e vir em qualquer circunstância, e não somente a privação de liberdade quando o adolescente estiver internado, como é tratada no Brasil. Essa mudança de concepção reforça o discurso e a prática de que o adolescente é responsabilizado pelos seus atos em todas as modalidades de medidas, e não somente quando privado de liberdade em regime de internação.

As medidas não privativas de liberdade, como são identificadas na Espanha, seriam no Brasil o que chamamos de medidas em meio aberto (liberdade assistida e prestação de serviço à comunidade). Para além dessas duas, que também são previstas e executadas no território espanhol, há a previsão de: "asistencia a un centro de día; convivencia con otra persona, familia o grupo educativo; realización de tareas socioeducativas; amonestación; privación del permiso de conducir ciclomotores o vehículos a motor" (ESPANHA, 2000). Aqui, pode-se identificar que algumas dessas alternativas se aproximam a medidas protetivas (art. 101 do ECA), porém, há uma distinção clara, nesse caso, que pressupõe responsabilização do adolescente (BRASIL, 1990). Ao tratar como medida sancionatória, e não protetiva, é também realizado o efeito da resposta social ao delito cometido.

Outro elemento determinante e diferencial não observado no componente legislativo brasileiro é a previsão de tratamento terapêutico como medida de intervenção ao delito. O registro aqui é o tratamento tanto a partir do diagnóstico de doenças e transtornos mentais quanto com relação à toxicodependência.

Enquanto no Brasil não há alternativas para esse atendimento e se referencia na rede de saúde pública o método de atendimento especializado para esses casos, na Espanha há previsão legal e unidades apropriadas para as medidas terapêuticas, sendo previsto o internamento terapêutico em regime fechado, semiaberto ou aberto, e ainda o tratamento ambulatorial. Essa não especialização no atendimento para adolescentes que cometem atos infracionais em virtude de transtornos/doenças mentais e/ou em decorrência do uso abusivo e dependência de drogas faz com que, nos 
casos mais graves, a única opção seja a internação. Ficam, assim, nas mesmas unidades os adolescentes com transtornos mentais e aqueles com dependência química, de modo que não é possibilitada uma especialização adequada do atendimento.

Toda essa estrutura ampla de possibilidades de intervenção com adolescentes infratores na Espanha evidencia uma clara opção pela alternativa da educação, em detrimento das práticas punitivas. O ECA pede a observância do princípio da brevidade e da excepcionalidade (BRASIL, 1990), e o Sinase (BRASIL, 2006), enquanto resolução do Conselho Nacional dos Direitos da Criança e do Adolescente (Conanda), aborda a necessidade de prevalência das medidas socioeducativas em meio aberto, em detrimento das medidas de restrição e privação de liberdade. Apesar disso, no que se refere à medida socioeducativa, ao que se assiste no Brasil é a prevalência da utilização da internação provisória e da internação.

Se realizarmos um recorte nos dados referentes às duas medidas similares de intervenção no Brasil e na Espanha - a internação em regime fechado (medida socioeducativa de internação) e a internação em regime semiaberto (medida socioeducativa de semiliberdade) -, fica demonstrado o real sentido de encarceramento de adolescentes para cada país:

Tabela 1 - Medidas de internação e semiliberdade na Espanha e no Brasil

\begin{tabular}{|c|c|c|c|c|c|c|c|c|}
\hline \multirow{2}{*}{$\begin{array}{c}\text { Tipo País } \\
\text { De Medida }\end{array}$} & \multicolumn{4}{|c|}{ Espanha } & \multicolumn{4}{|c|}{ Brasil } \\
\cline { 2 - 9 } & \multicolumn{2}{|c|}{2012} & \multicolumn{2}{|c|}{2013} & \multicolumn{2}{|c|}{2012} & \multicolumn{2}{c|}{2013} \\
\cline { 2 - 9 } & Ad. & $\%$ & Ad. & $\%$ & Ad. & $\%$ & Ad. & $\%$ \\
\hline Semiliberdade & 3.692 & $84 \%$ & 3.887 & $85 \%$ & 1.860 & $9 \%$ & 2.272 & $10 \%$ \\
\hline Internação & 713 & $16 \%$ & 704 & $15 \%$ & 18.572 & $91 \%$ & 20.794 & $90 \%$ \\
\hline
\end{tabular}

Fonte: dados compilados pelo autor, 2016.

Torna-se evidente a prevalência da alternativa mais grave no Brasil; já na Espanha, a privação de liberdade é utilizada somente em casos extremos. Por mais que no Brasil a previsão legal também defina isso, na prática há uma inversão. Na realidade espanhola, se considerados só os adolescentes em internação e semiliberdade, $84 \%$ das medidas aplicadas são de semiliberdade e $16 \%$, de internação em regime fechado. No Brasil, essa lógica se inverte: para cada dez adolescentes com medidas socioeducativas de internação, nove estão em restrição total de liberdade (internados) e um está em semiliberdade, ou seja, a opção é o encarceramento. 
Outro dado preocupante que pode ser constatado no quadro é o aumento contínuo no número de internações no Brasil entre os anos de 2012 e 2013, enquanto que na Espanha os dados são de estabilidade. Pela falta de dados técnicos no Brasil não é possível compreender se há um real aumento no número de atos infracionais ou somente um aumento no número de medidas aplicadas.

Outra impossibilidade percebida na análise no Brasil, tendo em vista a falta de dados confiáveis, é a relação entre as medidas socioeducativas em meio aberto e as medidas de restrição e privação de liberdade. Nesses casos, não existem dados sistematizados com metodologia científica confiável relativos às medidas socioeducativas em meio aberto. Esse elemento, por si só, já é fator determinante que prejudica a avaliação sistemática dessa política pública.

Enquanto isso, na Espanha, a Dirección general de servicios para la familia y la infancia, dependente do Ministerio de Sanidad, Servicios Sociales e Igualdad del Gobierno de España, através do Observatório da Infância, emite boletins anuais com os dados estatísticos concernentes aos menores infratores. Nesse levantamento, já citado anteriormente, podemos constatar ainda que, do total das medidas judiciais executadas, a privação de liberdade (considerando os regimes fechados espanhóis) não passa de $13 \%$ das medidas aplicadas. Ou seja, há de fato a prevalência das medidas menos graves e alternativas à privação de liberdade, em detrimento da alternativa punitiva:

\section{Gráfico 1 - Porcentagem por tipo de medida aplicada} a menores infratores na Espanha - 2013
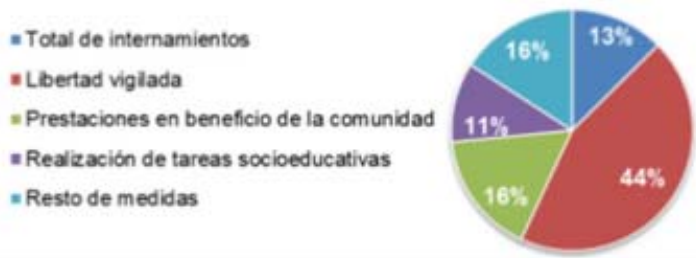

Fonte: OBSERVATORIO DE LA INFANCIA, 2013.

No que se refere ao panorama legal normativo, a legislação brasileira tem registros bastante progressistas e inovadores, como por exemplo a previsão dos princípios que devem reger a medida socioeducativa (art. 35 da Lei do Sinase 12.594/2012) (BRASIL, 2012). A legislação, além da individualização do atendimento, prevê a construção do Plano Individual de Atendimento (PIA); porém, há um distanciamento entre essas previsões e as práticas no cumprimento das medidas socioeducativas. No referencial 
legal espanhol, por sua vez, há registros de avanços quanto à individualização nas normativas dos centros de internação:

Los centros estarán divididos en módulos adecuados a la edad, madurez, necesidades y habilidades sociales de los menores internados y se regirán por una normativa de funcionamiento interno cuyo cumplimiento tendrá como finalidad la consecución de una convivencia ordenada, que permita la ejecución de los diferentes programas de intervención educativa y las funciones de custodia de los menores internados. (FUNDAÇÃO ATENEA, 2014, p. 13).

Há, então, o respeito às práticas quanto a essa normativa legal, enquanto que no Brasil as unidades não conseguem sequer garantir direitos à divisão dos adolescentes internados no interior das unidades, como separação por critérios de idade, compleição física e gravidade na infração (art. 123 do ECA - BRASIL, 1990), nem mesmo garante atividades pedagógicas. Quiçá um dia veremos a consolidação de uma metodologia que efetive os planos individuais de atendimento.

Ainda nessa lógica da previsão legal, a Lei do Sinase No. 12.594 de 2012 (BRASIL, 2012), assim como a LO n. 5/2000' (ESPANHA, 2000a), prevê que os adolescentes deverão cumprir medidas em meio aberto quando não houver vagas de internação em centros de privação de liberdade. Entretanto, no Brasil, mesmo quatro anos após a aprovação da lei, ela não foi colocada em prática. O que se assiste é ao inchaço do sistema, com unidades superlotadas.

$\mathrm{Na}$ Espanha não há unidades superlotadas. O critério legal para cumprir a medida socioeducativa alternativa de privação em caso de não haver vagas é respeitado. Apesar disso, o dado mais importante é que esse critério é muito pouco utilizado, considerando dados da Dirección general de servicios para la familia y la infancia (FUNDAÇÃO ATENEA, 2014), que dizem que, em 2012, existiam na Espanha 90 centros de internação de menores com 2.944 vagas.

No Brasil, outro dado preocupante, como prioridade clara para a opção de encarceramento, é que, no contexto do atendimento socioeducativo a partir do levantamento da Secretaria Nacional de Direitos Humanos (BRASIL, 2012a), todo o reforço do investimento foi realizado na construção de unidades de privação de liberdade (internação provisória e internação), em detrimento da construção de espaços de restrição de liberdade (semiliberdade) (Tabela 2).

Para além desses dados, o que se evidencia como grande avanço na política de atendimento a adolescentes infratores na Espanha são os programas oferecidos no contexto das Comunidades Autônomas, que propõem alternativas e tratamentos que priorizam ainda mais a individualização

${ }^{1}$ LEY ORGÁNICA 5/2000, de 12 de enero, reguladora de la responsabilidad penal de los menores. 
Tabela 2 - Unidades socioeducativas no Brasil - 2010/2011 Unidades Socioeducativas

\begin{tabular}{|c|c|c|c|}
\hline & \multicolumn{3}{|c|}{ Unidades Socioeducativas } \\
\hline \multirow{6}{*}{ 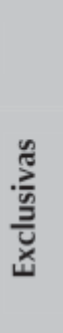 } & \multirow{2}{*}{ Programas } & \multicolumn{2}{|c|}{ Instituições } \\
\hline & & 2010 & 2011 \\
\hline & Internação & 124 & 123 \\
\hline & Internação Provisória & 55 & 43 \\
\hline & Semiliberdade & 110 & 110 \\
\hline & Atendimento Inicial & 16 & 10 \\
\hline$\frac{\pi}{n}$ & $\begin{array}{l}\text { Internação, Internação } \\
\text { Provisória e Atendimento } \\
\text { Inicial }\end{array}$ & 130 & 162 \\
\hline & & 435 & 448 \\
\hline
\end{tabular}

Fonte: BRASIL, 2012aㅗ

no atendimento. Em visita do pesquisador à Agencia de La Comunidad de Madrid para La Reeducación y Reinsercón del Menor Infractor, órgão responsável pela política de atendimento a adolescentes infratores da Comunidade Autónoma de Madrid - organismo autônomo, dependente da Consejería de Presidencia, Justicia e Interior de la Comunidade de Madrid -, foi possível conhecer o Programa Central de Tratamiento Educativo y Terapeutico para Menores Infractores. Nesse documento, que reflete as práticas do órgão em questão, fica evidenciado o desenvolvimento de numerosos programas e autuações, entendendo que só com o avanço da investigação e dos conhecimentos científicos atuais pode-se obter maior garantia de alcançar os objetivos.

Muitos desses programas desenvolvidos são pioneiros não só na Espanha, como também internacionalmente:

[...] firmándose numerosos Convenios de colaboración con diferentes países europeos e hispanoamericanos, con Universidades y organismos académicos y con asociaciones sinánimo de lucro que apoyan la labor con los menores infractores. Los programas desarrollados desde la Agencia en colaboración con universidades o asociaciones de reconocido prestigio, expertas en la materia de que se trate, van dirigidos, entre otros, a menores que cumplen medida judicial por delitos de agresión sexual, a aquellos que han cometido violencia 
filioparental, que presentan problemas de consumo de drogas o trastornos significativos de la conducta. (GOMEZ; BIEZMA, 2014, p. 5).

A parceria com universidades possibilita a construção de programas que especifiquem o tratamento mais adequado para cada tipo de intervenção com os adolescentes. Além disso, retrata que a atuação com os menores infratores deve se apoiar em três bases fundamentais de intervenção, bem como numa quarta, que atende ao contexto familiar:

1. La intervención educativa y formativa en todos sus amplios contenidos: escolarización, formación profesional, deporte, educación no formal con las rutinas de la vida cotidiana, actividades de educación en valores y desarrollo personal.

2. La inserción laboral, como eje fundamental de inserción social, que comprende tanto desde el primer momento de búsqueda de empleo y desarrollo de las aptitudes para conseguirlo como el mantenimiento y el apoyo al menor durante el desarrollo y consolidación en el mismo. 3. La intervención terapéutica y profesional que atienda las necesidades criminógenas específicas, es decir, los factores de riesgo dinámicos presentes en cada caso. En este sentido, la Agencia desarrolla trabajos pioneros $y$, entendemos, de especial interés como el desarrollo de Programas Generales y Especializados de Tratamiento.

4. Debemos añadir a estos tres ejes un cuarto aspecto, que si bien ya se abordaba, sigue cobrando vital importancia a medida que avanzamos en el trabajo investigador y en la recogida de datos, y éste no es otro que la intervención con la familia. La información que obtenemos desde diferentes ámbitos, corrobora el papel fundamental de la interrelación familiar: el maltrato familiar ascendente o violencia filioparental, la pertenencia a grupos violentos o su influencia en el desarrollo de las carreras delictivas de los menores son algunos aspectos en los que la ascendencia de la família se revela como fundamental. (GOMEZ; BIEZMA, 2014, p. 5).

A individualização do tratamento é um dos eixos fundamentais desses programas de intervenção. O art. 27.1 da LO n. 5/2000 aponta "sobre la situación psicológica, educativa y familiar del menor, así como sobre su entorno social, y en general sobre cualquier outra circunstância relevante a los efectos de la adopción de alguma de las medidas prevista" (ESPANHA, 2000a). Nessa previsão, há um valor fundamental, não só no sentido de personalizar o tratamento, mas também no de entender o ato delitivo como uma compreensão e resposta específica. Considera-se, assim, que as circunstâncias a que se referem a prática do ato infracional devem marcar a especificidade tanto do menor sujeito da intervenção como do delito, que, finalmente, não é senão uma atuação concreta e determinada da pessoa.

Nesse sentido, ficou evidenciado que as oportunidades a alternativas para o atendimento aos adolescentes infratores vão além das previsões legais. É reforçado o papel do Estado na busca de alternativas para amenizar o efeito punitivo e a utilização das medidas mais graves, 
além de ficar manifestada a necessidade da construção de propostas metodológicas de intervenção que privilegiem o atendimento individual. No contexto do Sinase, somente a previsão legal para a realização dos planos individuais de atendimento não tem sido suficiente para garantir a realização dos mesmos. É, portanto, uma alternativa para sua concretização a parceria com as universidades, como acontece no caso da Comunidade Autônoma de Madrid.

\section{Maioridade penal no Brasil e na Espanha: o pêndulo punitivo sobre os adolescentes infratores}

É importante salientar que Brasil e Espanha respeitam os princípios das normas preconizadas pela Organização das Nações Unidas (ONU), que regulamenta a atuação com adolescentes infratores, da qual os dois países são signatários. Porém, o Brasil adota um modelo de proteção integral, que teve início com o ECA, em 1990; já a Espanha adota um modelo de responsabilidade penal juvenil. Ambos os modelos obedecem a uma perspectiva sancionatória-educativa, considerando sempre o superior interesse do menor. A adoção desses dois modelos diferentes será determinante para subsidiar a discussão acerca da redução da maioridade penal nesses dois países.

Na Espanha, até a entrada em vigor do novo Código Penal de 25 de maio de 1996 (ESPANHA, 1996), a idade penal estava situada em 16 anos, mas foi elevada para 18 anos. Ou seja, considerava-se imputável um menor a partir dessa idade, capacitando-o a ser submetido ao processo incriminador de caráter penal a partir dos 16 anos. Na prática, a elevação da idade não entrou em vigor em 1996, mas se efetivou somente em 2000, com a lei que regulamentou a responsabilidade penal dos menores de 18 anos.

Assim, a maioridade penal na Espanha pode ser compreendida, como estabelecem Cuesta e Blanco (2006, p. 7), da seguinte forma:

En primer lugar, se han elevado los límites de edad y,tras la última reforma, la jurisdicción de menores sólo se ocupa de hechos y conductas cometidos por personas entre 14 y 18 años. Además, el límite de 18 años no puede ser considerado ya un limite absoluto de responsabilidad penal, puesto que el nuevo sistema es un sistema de 'responsabilidade penal': los menores de 18 años pueden ser también declarados responsables si cometen una de las infracciones tipificadas por la legislación penal. Con arreglo al nuevo modelo, los menores de 14 son los únicos que no pueden ser penalmente responsables (art. 4). Por consiguiente, la minoría de edad (18) sólo impide la aplicación del CP de adultos; pero la declaración de responsabilidad penal únicamente puede darse en ausencia de causas de justificación, inimputabilidad o exculpación; requisito necesario para ser penal- 
mente responsable es, pues, también la culpabilidad, y los menores de 18 (pero mayores de 14) pueden ser imputables, capaces de culpabilidad. En definitiva, ha de entenderse que, a pesar de las apariencias, la LO 5/2000 rebajó a 14 el límite mínimo de la imputabilidad, si bien, entre 14 y 18 años, el sistema establecido para declarar la responsabilidade penal es un sistema sustantivo, procesal y ejecutivo especial.

Atualmente, a idade penal mínima é de 14 anos. Contudo, há uma lei específica para menores entre 14 e 18 anos, diferente do que é estabelecido para os adultos, ou seja, podemos falar em direito penal juvenil. A idade máxima estabelecida para que se aplique a lei aos menores que cometem delitos está pautada em 18 anos, mas a lei pode ser aplicada a pessoas maiores de 18 e menores de 21 quando o juiz de instrução assim o considerar. Nesse sentido:

Los menores de 18 años no son responsables conforme a éste, sino de acuerdo con la Ley de responsabilidad penal de los menores (que no habla de responsabilidad personal ni social, sino claramente penal). En lo relativo a la edad inferior (actualmente, los catorce años), no siempre ha sido la misma; incluso, en el momento presente, un sector social aboga por su establecimiento em los doce años, a diferencia de por arriba, en que el límite de los dieciocho años no encuentra crítica alguna (una vez derrogada definitivamente la posibilidad contemplada en la LO de 2000 de extender su competencia a los jóvenes de edad comprendida entre los dieciocho y los veintiún años, posibilidad que nunca entró em vigor, tras sucesivas suspensiones legales). (OSTOS, 2011, p. 38).

É interessante a constatação de que a evolução legal na Espanha, em relação ao atendimento a adolescentes infratores, experimentou o rebaixamento da maioridade penal para 16 anos (em 1992) - clamor a que se assiste no Brasil e na América Latina -, e voltou para 18 anos (em 1996, entrando em vigor somente em 2000, com a LO n. 5/2000), como uma tendência internacional. Porém, ao estabelecer em 14-15 anos ou 16-17 anos, cria-se um paradoxo de direito penal juvenil, utilizando as mesmas terminologias do sistema penal adulto, mas com diretrizes de atendimento próprias. O que ocorreu na Espanha também foi a passagem da doutrina de situação irregular para a doutrina com princípios da proteção integral, contudo, sob a normativa do direito penal juvenil.

No entanto, a Espanha cede aos clamores sociais quanto ao endurecimento da normativa penal em relação aos menores, que se manifestou com a reforma legal de dezembro de 2006. Tais mudanças na legislação atenderam a anseios populares e reforçam o caráter punitivo do Estado penal da política espanhola. Deste modo, essa reforma é posterior às sucessivas reformas (ESPANHA, 2000b; ESPANHA 2000a; ESPANHA, 2006), promovidas com o objetivo de prover à nova lei ferramentas necessárias 
para adaptar-se à realidade dos menores que cometem atos delitivos considerados graves. Nesse sentido, ficou evidente que a mudança do panorama legal, elevando a idade penal de 16 para 18 anos, ocorreu por pressão da comunidade internacional, e não por uma preocupação com a melhor forma de responsabilização desses sujeitos. Essa constatação se dá a partir do momento em que, na primeira oportunidade, é realizada uma reforma aumentando o tempo de privação de liberdade para esses adolescentes.

Observamos a construção de uma resposta mais contundente à delinquência juvenil de especial intensidade, que foi intitulada por alguns autores como excessiva (BERNUZ; FERNÁNDEZ; PÉREZ, 2008) e acabou por tomar parte do todo da legislação. Apresenta-se na prática como ineficaz, do ponto de vista da intervenção educativa, já que existe a crença generalizada entre os agentes do sistema de justiça de menores de que os avanços que se conseguem em um ano, na soma dos demais anos de intervenção e privação de liberdade, dificilmente serão novamente alcançados (GARRIDO GENOVVÉS; MONTORO GONZÁLEZ, 1992). Assim, trata-se de uma medida simbólica, porque muitas de suas premissas não intentam acalmar o alarde social promovido pela delinquência juvenil violenta (FERNÁNDEZ MOLINA, 2012).

Essas mudanças na regulamentação, efetuadas a partir de 2006, não são só excessivas, ineficazes e simbólicas, mas também promovem, em algumas previsões legais, uma clara violação dos tratos internacionais ratificados pela Espanha, mais concretamente o da Convenção de Direitos de Crianças e Adolescentes de 1989 (FUNDAÇÃO ATENEA, 2014). As recomendações que realizam as Nações Unidas aos Estados firmam que a privação de liberdade deve ser sempre a última medida, executada quando sejam esgotadas todas as possibilidades anteriores (FERNÁNDEZ MOLINA, 2012), incluindo aqui uma medida menos grave do que a aplicada aos adultos.

Assim, é possível compreender essas mudanças legais a partir da tabela que segue com o registro da aplicação de medidas em função da idade. Em comparação entre a LO n. 5/2000 de 12 de janeiro de 2000 (ESPANHA, 2000a), e a LO n. 8/2006, de 5 de dezembro de 2006 (ESPANHA, 2006), podemos estabelecer as seguintes conclusões (tabela 3).

Esse endurecimento na norma fez com que os prazos de cumprimento das penas, em regime aberto ou fechado, fossem alterados. As penas aplicadas a jovens de 14 a 15 anos, que eram de no máximo dois anos, foram alteradas para até cinco anos. Para os jovens de 16 a 18 anos, as penas máximas passaram de cinco para oito anos. Entretanto, a mudança mais polêmica é o conceito de "período de seguridade", que prevê, para crimes de extrema gravidade (assassinato ou terrorismo), a possibilidade de o adolescente jovem, ao completar 18 anos, mesmo já tendo cumprido um período da medida no sistema penal juvenil, ser transferido para um presídio comum, de acordo com a decisão do juiz. 
Tabela 3 - Registro da aplicação de medidas em função da idade

\begin{tabular}{|c|c|c|c|c|}
\hline $\begin{array}{l}\text { Edad-Ley/ } \\
\text { Delito }\end{array}$ & $\begin{array}{l}\text { 14-16 años } \\
\text { LORPM }\end{array}$ & $\begin{array}{l}\text { 14-16 años } \\
\text { L0 8/2006 }\end{array}$ & $\begin{array}{l}\text { 17-18 años } \\
\text { LORPM }\end{array}$ & $\begin{array}{l}\text { 17-18 años } \\
\text { L0 8/2006 }\end{array}$ \\
\hline $\begin{array}{l}\text { Con violencia o } \\
\text { intimidación } \\
\text { o con grave riesgo }\end{array}$ & $\begin{array}{l}2 \text { años máximo. } \\
\text { Puede aplicarse } \\
\text { régimen } \\
\text { cerrado }\end{array}$ & $\begin{array}{l}3 \text { años máximo. } \\
\text { Puede aplicarse } \\
\text { régimen cerrado }\end{array}$ & $\begin{array}{l}\text { Hasta } 5 \text { años. } \\
\text { Puede imponerse } \\
\text { régimen cerrado }\end{array}$ & $\begin{array}{l}\text { Hasta } 6 \text { años. } \\
\text { Puede imponerse } \\
\text { régimen cerrado }\end{array}$ \\
\hline Extrema gravedad & $\begin{array}{l}2 \text { años máximo. } \\
\text { Puede aplicarse } \\
\text { régimen } \\
\text { cerrado }\end{array}$ & $\begin{array}{l}3 \text { años máximo. } \\
\text { Puede aplicarse } \\
\text { régimen cerrado }\end{array}$ & $\begin{array}{l}\text { Régimen cerrado } \\
\text { de } 1 \text { a } 5 \text { años. } \\
\text { Periodo de seguridad } \\
\text { hasta transcurrido } 1 \\
\text { año de cumplimiento. }\end{array}$ & $\begin{array}{l}\text { Régimen cerrado } \\
\text { de } 1 \text { a } 6 \text { años. } \\
\text { Periodo de seguridad } \\
\text { hasta transcurrido } 1 \\
\text { año de cumplimiento }\end{array}$ \\
\hline $\begin{array}{l}\text { Asesinato, violación, } \\
\text { terrorismo }\end{array}$ & $\begin{array}{l}\text { Necesariamente } \\
\text { régimen cerrado de } 1 \\
\text { a } 4 \text { años. } \\
\text { En concursos de } \\
\text { delitos } \\
\text { hasta } 5 \text { años }\end{array}$ & $\begin{array}{l}\text { Necesariamente } \\
\text { régimen cerrado de1 } \\
\text { a } 5 \text { años. } \\
\text { En concurso de } \\
\text { delitos hasta } 6 \text { años }\end{array}$ & $\begin{array}{l}\text { Necesariamente } \\
\text { régimen cerrado de } 1 \\
\text { a } 8 \text { años. } \\
\text { Periodo de seguridad } \\
\text { la mitad de la } \\
\text { medida. En concurso } \\
\text { de delitos } \\
\text { (necesariamente uno } \\
\text { de ellos terrorismo) } \\
\text { hasta } 10 \text { años }\end{array}$ & $\begin{array}{l}\text { Necesariamente } \\
\text { régimen cerrado de } 1 \\
\text { a } 8 \text { años. Periodo de } \\
\text { seguridad la mitad de } \\
\text { la medida. En } \\
\text { concurso de delitos } \\
\text { hasta } 10 \text { años }\end{array}$ \\
\hline $\begin{array}{l}\text { Delitos graves o } \\
\text { delitos } \\
\text { actuando en banda, } \\
\text { organización o } \\
\text { asociación }\end{array}$ & & $\begin{array}{l}3 \text { años máximo. } \\
\text { Puede aplicarse } \\
\text { régimen } \\
\text { cerrado }\end{array}$ & & $\begin{array}{l}\text { Hasta } 6 \text { años. Puede } \\
\text { imponerse régimen } \\
\text { cerrado. En caso de } \\
\text { extrema gravedad } \\
\text { necesariamente } \\
\text { régimen cerrado de } 1 \\
\text { a } 6 \text { años }\end{array}$ \\
\hline
\end{tabular}

Fonte: FERNÁNDEZ; TARANCÓN, 2010.

No Brasil, assiste-se a um clamor social, motivado por sentimento de vingança e pela lógica perversa punitiva, para mudanças no panorama legal e uma maior punição para os adolescentes infratores, seja pela redução da maioridade penal, seja pelo aumento do tempo da medida socioeducativa de internação. A Constituição Federal de 1988, em seu artigo 228, (BRASIL, 1988) deixa claro que são penalmente inimputáveis os menores de 18 anos sujeitos às normas da legislação especial. Atualmente, o ECA considera como sendo criança a pessoa de até 12 anos de idade incompletos, e adolescente, aquela entre 12 e 18 anos de idade. Os adolescentes autores de atos infracionais são passíveis de receber as medidas socioeducativas, sendo a mais grave a medida socioeducativa de internação. De acordo com esse estatuto, em nenhuma hipótese o período máximo de internação deverá exceder a três anos.

Em 2015 voltaram à tona no Congresso Nacional votações de projetos de lei que diminuem a maioridade penal de 18 para 16 anos, sendo na verdade uma Proposta de Emenda Constitucional (PEC). Inicialmente, a proposta de redução da maioridade para 16 anos foi rejeitada pela Câmara dos Deputados, porém, houve uma manobra por parte do 
presidente da Câmara para que o projeto inicial voltasse para votação, dessa vez, sendo aprovado.

O texto aprovado sugere que adolescentes a partir de 16 anos podem receber pena e ser julgados como adultos, mas somente em casos nos quais os crimes forem cometidos com violência ou grave ameaça, tais quais crimes hediondos, homicídio doloso, lesão corporal grave ou lesão seguida de morte. A diferença em relação ao texto que foi reprovado pela Câmara no dia anterior é que foram excluídos da redução os crimes de tráfico e roubo qualificado. Entretanto, para que essa medida avance necessita-se ainda de análise de comissões internas da Câmara, votação em segundo turno e posterior votação no Senado.

Ainda têm surgido discussões que apontam como alternativa a necessidade de se ampliarem os estudos acerca do aumento do tempo da medida socioeducativa de internação, que hoje tem como limite máximo três anos. Nessa lógica, são apontadas variáveis que levam em consideração a idade do adolescente (alternativas diferentes para quem tem 12 anos e para quem tem 16 ou 17 anos) e, ainda, a natureza do ato infracional cometido. Não é, assim, uma mudança que afeta todo o sistema de atendimento socioeducativo, mas sim uma parcela de adolescentes que cometem atos infracionais com violência ou grave ameaça à pessoa, aumentando o tempo de internação para esses atos de natureza grave.

A questão é que essa "pseudoalternativa" continua agindo no efeito, e não na causa. Reforça e atende aos clamores sociais de que a imposição de uma lei mais rígida possa influenciar na redução dos índices de violência, mas que, na verdade contempla o desejo de vingança (travestido de justiça) de uma parcela significativa da sociedade. Tal possibilidade só reforça a atual lógica punitiva perversa, na qual o que impera é a vontade de "dar o troco", estigmatizar e segregar, reproduzindo historicamente uma tradição da sociedade burguesa de sempre eleger os "inimigos da ordem" entre os membros das classes subalternatizadas pelo capital.

Há uma necessidade urgente de melhor qualificar essa discussão. Não se trata apenas de defender uma posição contrária à redução da maioridade penal pura e simples; temos que sair do superficial e analisar a complexidade desse fenômeno. Faz-se mister enxergar que estamos falando da responsabilização penal de adolescentes e jovens pobres, parcela excluída até do trabalho formal exercido pela classe trabalhadora, pauperizada e que, muitas vezes, não é considerada nem para o exército industrial de reserva.

Tem que haver mudanças de paradigmas para que haja mudanças na prática. O que deve ser abordado é o controle social imposto; não só o controle estatal, mas aquele a serviço do capital, mediado pelas relações de poder estabelecidas pela sociedade capitalista, do Estado e da sociedade. Estamos falando de regulação e de dominação, uma reprodução da lógica do capital. Se ainda ficarmos inventando alternativas, só estaremos a serviço dos ideais da classe dominante. 
É possível observar, assim, que se trata de um movimento do mesmo pêndulo burguês que tende ao cerceamento de direitos e à punição que ocorreu na Espanha. No Brasil, essas mudanças no panorama legal tendem a demorar mais para acontecer; contudo, o movimento hegemônico, essa construção de cima para baixo, com viés punitivo do aparato de controle social, continua a aumentar, a fim de punir os "eleitos" como inimigos da ordem: esses adolescentes, que acabam por serem acorrentados à cultura da punição. São os condenados historicamente ao que Freire (2007) definiu como "pena de morte social".

Para concluir essa análise, é preciso ressaltar a opção da normativa da Espanha pelo Direito Penal Juvenil, ou seja, o conceito central é o de aplicação de uma pena. No caso brasileiro, pela adoção do ECA como um modelo de proteção integral, é utilizado o termo medida socioeducativa. Essa sutil, porém determinante diferença conceitual, aponta para outra contradição evidenciada no presente estudo: enquanto a Espanha utiliza o termo pena, são as formas de aplicação e execução das medidas socioeducativas no Brasil que realmente punem os adolescentes. Ou seja, aqui assistimos a um sistema majoritariamente punitivo, no qual a principal alternativa é o encarceramento. Apesar disso, não são poucos os reforços de um discurso positivo de "internação em centros de socioeducação", que mascara o que realmente acontece com esses adolescentes.

Não há aqui a defesa ingênua de que a simples mudança de normativa para a adoção do direito penal juvenil seja capaz de superar os estigmas e discussões acerca da redução da maioridade penal. Entretanto, como discutido anteriormente, sem o necessário debate acerca de como o adolescente autor de ato infracional no Brasil tem sido responsabilizado e penalizado não será possível conter essa gana por vinganças, que tem no discurso da redução da maioridade penal um mantra a favor do controle social e de um Estado cada vez mais punitivo.

Torna-se necessária a compreensão desse contexto a partir do conceito de questão social, como resultado das contradições inerentes à sociabilidade do capital, bem como do contexto da delinquência juvenil e da consequente política de encarceramento em massa dessa juventude pobre como uma "nova" face da questão social.

Em outras palavras, tratamos de uma questão inscrita na dinâmica de classe e circunscrita ao âmbito do capital, como já dito. Ela é apreendida como expressão ampliada das desigualdades sociais, fundadas pela sociabilidade do capital. O que se assiste é a um discurso preocupado em gerenciar as mazelas da questão social, sem problematizar a sociabilidade do capital e, com ela, a ordem econômica estabelecida, da qual não é senão sua expressão.

No âmbito do pensamento liberal, a objetividade da 'questão social' é dissolvida em torno da polêmica entre a responsabilidade pública 


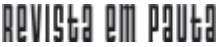

\} MAIORIDADE PENAL NO BRASIL E NA ESPANHA - PEIXOTO, R. B.

DOI: $10.12957 /$ REP.2019.42508

de resolvê-la através do Estado ou da sociedade civil e da responsabilidade individual daqueles que sofrem o tormento da miséria. Essa polêmica continua muito presente na atualidade, principalmente por parte dos representantes do neoliberalismo que defendem a desresponsabilização do Estado ante as sequelas da 'questão social'. (PIMENTEL, 2012, p. 16).

Fica evidente, tanto no Brasil quanto na Espanha, a percepção de que na raiz da "questão social" encontram-se políticas governamentais favorecedores da esfera financeira e do grande capital produtivo. Além disso, que a execução de uma política de atendimento a adolescentes em conflito com a lei nada mais é do que a reprodução dessa mesma lógica. Se não houver uma discussão pormenorizada do papel do Estado na execução de políticas públicas, sem antes compreender e apreender a lógica implicada pelo capital, haverá um reforço do favorecimento do grande capital produtivo. 


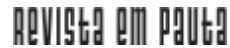

\} MAIORIDADE PENAL NO BRASIL E NA ESPANHA - PEIXOTO, R. B. \}

DOI: $10.12957 /$ REP.2019.42508

\section{Referências}

BERNUZ, M. J.; FERNÁNDEZ, E.; PÉREZ, F. Educar y controlar: la intervención comunitaria en la justicia de menores. Revista Electrónica de Ciencia Penal y Criminología, 2008.

BRASIL. Lei 12.594, de 18 de janeiro de 2012. Institui o Sistema Nacional de Atendimento Socioeducativo (SINASE),. Diário Oficial da União, Brasília, 18 jan. 2012.

BRASIL. Secretaria Especial dos Direitos Humanos; Conselho Nacional dos Direitos da Criança e do Adolescente. Levantamento Nacional do Sistema de Atendimento Socioeducativo (Sinase). Brasília: SDH, $2012 a$.

BRASIL. Secretaria Especial dos Direitos Humanos; Conselho Nacional dos Direitos da Criança e do Adolescente. Sistema Nacional de Atendimento Socioeducativo (Sinase). Brasília: Conanda, 2006.

BRASIL. Constituição (1888). Constituição da República Federativa do Brasil de 1988. Diário Oficial [da] República Federativa do Brasil, Brasília, DF, 08 out. 1998.

BRASIL. Lei Federal n. 8.069, de 13 de julho de 1990. Dispõe sobre o Estatuto da Criança e do Adolescente e dá outras providências. Diário Oficial [da] República Federativa do Brasil, Brasília, 13 jul. 1990.

CUESTA, J. L.; BLANCO, I. El enjuiciamiento de menores y jóvenes infractores en España. Barcelona, Editora Única, 2006.

ESPANHA. Ley Orgánica n. 8/2006, de 4 de diciembre, por la que se modifica la Ley Orgánica n. 5/2000, de 12 de enero, reguladora de la responsabilidad penal de los menores. BOE, n. 290, 5 dic. 2006.

ESPANHA. Ley Orgánica n. 5/2000, de 12 de enero. Regula la responsabilidad penal de los menores. BOE, n. 11, 13 ene. 2000a.

ESPANHA. Ley Orgánica n. 7/2000, de 22 de diciembre. Modifica la Ley Orgánica n. 10/1995, de 23 de noviembre, del Código Penal, y de la Ley Orgánica n. 5/2000, de 12 de enero, reguladora de la Responsabilidad Penal de los Menores, en relación con los delitos de terrorismo. BOE, n. 307, 23 dic. 2000b.

ESPANHA, Ley Organica, el Código Penal. BOE no 283, 25 de maio de 1996.

FERNÁNDEZ MOLINA, E. El internamento de menores: una mirada hacia la realidad de su aplicación en España. Revista Electrónica de Ciencia Penal y Criminología, n. 14-18, 2012.

FREIRE, S. M. O fetiche do enfrentamento da pobreza no Brasil: nem direitos, nem humanos. In: FREIRE, S. de M. (org.). Direitos humanos: violência e 


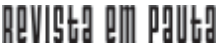

\} MAIORIDADE PENAL NO BRASIL E NA ESPANHA - PEIXOTO, R. B. \}

DOI: $10.12957 /$ REP.2019.42508

pobreza na América Latina contemporânea. Rio de Janeiro: Letra e Imagem, 2007.

FUNDAÇÃO ATENEA. Desarrollo de programas de prevención en centros de internamiento de menores. Madrid, jun. 2014.

GARRIDO GENOVÉS, V.; MONTORO GONZÁLEZ, L. La reeducación del delincuente juvenil. Los programas de éxito. Valencia: Tirant lo Blanch, 1992.

GOMEZ, J. L.; BIEZMA, M. J. R. Programa central de tratamento educativo e terapêutico para menores infratores. Madrid: Universidad Complutense de Madrid, 2014.

OBSERVATÓRIO DE LA INFANCIA. Estadística básica de medidas de protección de la infancia. Boletín 14. España: Ministerio de Sanidad, Servicios Sociales e lgualdad, 2013.

OSTOS, J. M. Noventa años de justicia penal de menores en España. Rev. Bras. Adolescência e Conflitualidade, n. 5, 2011.

PIMENTEL, E. Uma "nova questão social"? Raízes materiais e humano-sociais do pauperismo de ontem e de hoje. São Paulo: Instituto Luckács, 2012.

DOI: 10.12957/rep.2019.42508

Recebido em 18 de janeiro de 2019.

Aprovado para publicação em 15 de fevereiro de 2019.

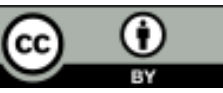

A Revista Em Pauta: Teoria Social e Realidade Contemporânea está licenciada com uma Licença Creative Commons Atribuição 4.0 Internacional. 